\title{
Long-Term Oxygen Therapy
}

Current Evidence and Practical, Day-to-Day Considerations

by Prof. Dr. med. Andreas Rembert Koczulla, Tessa Schneeberger, MSc. PT; Dr. rer. med. Inga Jarosch, Dr. med. Klaus Kenn, and Dr. phil. Rainer Gloeckl in issue 51-52/2018

\section{Oxygen Therapy for Isolated Exercise-Induced Hypoxemia Should Be Prescribed With Caution}

In confirmed resting hypoxemia (oxygen partial pressure $\left[\mathrm{pO}_{2}\right]$ $\leq 55 \mathrm{~mm} \mathrm{Hg}$ ) over a period of 4 weeks, long-term oxygen therapy (LTOT) can improve patients' prognosis. Twenty-four percent of our blood gas analyses with LTOT indication had a $\mathrm{pO}_{2}$ of exactly $55 \mathrm{~mm} \mathrm{Hg}$.

In patients with moderate exercise-induced hypoxemia (pulse oximetry saturation $\left[\mathrm{SpO}_{2}\right] \quad 80-88 \%$ ) and resting $\mathrm{pO}_{2}$ $>55 \mathrm{mmHg}$, oxygen therapy, however, should be viewed critically. In our opinion, prescription of oxygen $\left(\mathrm{O}_{2}\right)$ therapy is too liberal in Germany in this setting, and is frequently not reviewed properly. Exercise-induced hypoxemia (median minimal exercise $\mathrm{SpO}_{2}$ of $84 \%$ ) with resting $\mathrm{pO}_{2}>55 \mathrm{~mm} \mathrm{Hg}$ was found in $29 \%$ of the 575 patients with chronic obstructive pulmonary disease (COPD) referred to our center in the period from 2015 to 2018 for lung transplantation (median forced expiratory volume in 1 second of $22 \%$ ). Sixty-three percent of this subgroup had a current $\mathrm{O}_{2}$ prescription (compare LOTT study: $33 \%$ ).

The effects of oxygen administration in patients with isolated exercise-induced hypoxemia are below the minimal clinically important difference. Air flow alone can alleviate shortness of breath. In a meta-analysis, oxygen administration on exertion improved the 6-minute walking distance (6MWD) in COPD patients only by $18.8 \mathrm{~m}$ compared to placebo (compressed air) (1). In a meta-analysis of 16 studies on COPD patients with exerciseinduced hypoxemia, dyspnea was reduced by oxygen administration only by 0.7 points on a scale from 0 to 10 , compared to placebo (2). Moreover, in 84 patients with pulmonary fibrosis and isolated exercise-induced hypoxemia, quality of life improved with oxygen therapy by just $4 \%$ in a 4 -week crossover study (oxygen administration versus no oxygen administration) and 6MWD only by $18.5 \mathrm{~m}$, compared to compressed air (3). Oxygen therapy has no effect on survival in patients with isolated exercise-induced hypoxemia.

Oxygen therapy is costly and associated with side effects. In patients with isolated exercise-induced hypoxemia, home oxygen therapy should only be prescribed if a mobile patient describes severe exercise-induced dyspnea, oxygen compared to compressed air has a clinically important effect and the patient is willing to use oxygen therapy.

DOI: $10.3238 /$ arztebl.2019.0287a

\section{References}

1. Bradley JM, O'Neill B: Short-term ambulatory oxygen for chronic obstructive pulmonary disease. Cochrane Database Syst Rev 2005; 4: CD00435.

2. Ekström M, Ahmadi Z, Bornefalk-Hermansson A, Abernethy A, Currow D: Oxygen for breathlessness in patients with chronic obstructive pulmonary disease who do not qualify for home oxygen therapy. Cochrane Database Syst Rev 2016; 11: CD006429.

3. Visca D, Mori L, Tsipouri V, et al.: Effect of ambulatory oxygen on quality of life for patients with fibrotic lung disease (AmbOx): a prospective, open-label, mixedmethod, crossover randomised controlled trial. Lancet Respir Med 2018; 6: 759-70.
4. Koczulla AR, Schneeberger T, Jarosch I, Kenn K, Gloeckl R: Long-term oxygen therapy - current evidence and practical, day to day considerations. Dtsch Arztebl Int 2018; 115: 871-7.

\section{Prof. Dr. med. Jens Gottlieb}

Deutsches Zentrum für Lungenforschung (DZL)

Medizinische Hochschule Hannover

Klinik für Pneumologie OE 6870

Hannover

Germany

Gottlieb.Jens@mh-hannover.de

\section{Dr. med. Martin Dierich}

Abteilung für Pneumologie

Klinik Bad Fallingbostel

Bad Fallingbostel

Germany

\section{PD. Dr. med. Thomas Fühner}

Klinik für Pneumologie und Beatmungsmedizin

Städtisches Klinikum Braunschweig

Braunschweig

Germany

PD. Dr. med. Heiko Golpon

Deutsches Zentrum für Lungenforschung (DZL)

Medizinische Hochschule Hannover

Klinik für Pneumologie OE 6870

Hannover

Germany

\section{In Reply:}

We would like to thank the authors of the letter for their contribution which is relevant to clinical practice.

We conducted a randomized, placebo-controlled, singleblind cross-over study on patients with chronic obstructive pulmonary disease and isolated exercise-induced hypoxemia and found a significant increase in 6-minute walking distance (6MWD) of $28 \mathrm{~m}$ with oxygen administration compared to compressed room air administration (1). This value lies within the range of the minimal clinically important difference which is assumed to be between $25 \mathrm{~m}$ and $33 \mathrm{~m}$. However, a closer look reveals significant interindividual differences with regard to these short-term oxygen effects: Only $47 \%$ of patients experienced a clinically relevant 6MWD improvement in response to oxygen administration. This is, of course, only a short-term effect and its clinical and prognostic significance is still not fully understood.

Both the British (2) and the German oxygen therapy guidelines (3) recommend to perform tests to establish the individual benefits (endurance capacity, $\mathrm{paO}_{2} \geq 60 \mathrm{mmHg}$ ) prior to prescribing outpatient oxygen therapy (level of evidence B). Against the background of a lack of data on long-term effects of oxygen therapy during exercising and the reported therapy-related costs, we think that this recommendation is reasonable. Therefore, we share the view of our colleagues from Hannover in terms of a personalized approach to prescribing oxygen therapy. 
We hope that the question of isolated exercise-induced hypoxemia, which is important and highly relevant for clinical practice, will be adequately reviewed in the update of the German guideline on oxygen therapy (which is currently being revised). Further studies are needed to improve our understanding in this matter.

DOI: 10.3238/arztebl.2019.0287b

\section{References}

1. Jarosch I, Gloeckl R, Damm E, et al.: Short-term effects of supplemental oxygen on 6-min walk test outcomes in patients with COPD: a randomized, placebo-controlled, single-blind, crossover trial. Chest 2017; 151: 795-803.

2. Hardinge M, Annandale J, Bourne S, et al.: British thoracic society guidelines for home oxygen use in adults. Thorax 2015; 70 (Suppl 1): i1-43.
3. Magnussen H, Kirsten AM, Köhler D, Morr H, Sitter H, Worth H: Leitlinien zur Langzeit-Sauerstofftherapie. Pneumologie 2008; 62: 748-56.

4. Koczulla AR, Schneeberger T, Jarosch I, Kenn K, Gloeckl R: Long-term oxygen therapy-current evidence and practical, day to day considerations. Dtsch Arztebl Int 2018; 115: 871-7

Corresponding author

Prof. Dr. med. Andreas Rembert Koczulla

Philipps-Universität Marburg (Standort Schönau)

Deutsches Zentrum für Lungenforschung (DZL)

Schön Klinik Berchtesgadener Land

Schönau am Königssee

Germany

rkoczulla@schoen-kliniken.de

\section{Conflict of interest statement}

The authors of both contributions declare that no conflict of interest exists.

\section{-O CLINICAL SNAPSHOT}

\section{Intestinal Manifestation of Polyangiitis with Massive Bleeding}

A 63-year-old man was brought to the hospital with massive peranal loss of bright-red blood. Three months earlier, p-ANCA/MPO-positive (ANCA, antineutrophil cytoplasmic antibody; MPO, myeloperoxidase), rapidly progressive glomerulonephritis had been diagnosed against a background of polyangiitis with acute-on-chronic renal failure requiring dialysis. The initial treatment was prednisolone and cyclophosphamide pulse therapy with plasmapheresis, but by the time of presentation to our department this had been switched to long-term treatment with prednisolone $7.5 \mathrm{mg} / \mathrm{day}$.

Emergency endoscopy revealed no source of bleeding in the upper intestinal tract down to beyond the ligament of Treitz, and ileocolonoscopy was also negative. Subsequent angiographic computed tomography found a solitary acute hemorrhage in the jejunum (Figure a). Because the patient had symptoms of shock, we proceeded to explorative laparotomy (Figure b) and intraoperative endoscopy via a lower intestinal enterotomy. This revealed segmental inflammation of the ileojejunum with fresh blood from ulcerations. Histological examination of resected jejunal tissue demonstrated granulomatous vasculitis. The patient was discharged 14 days later after renewed cyclophosphamide and cortisone pulse therapy without further complications.

Systemic vasculitis of the gastrointestinal tract manifests itself in 30 to $55 \%$ of cases, depending on type; biopsy rarely confirms the diagnosis. Involvement of the small intestine has a potentially grave prognosis, as perforations or hemorrhages can very quickly become life-threatening.

Prof. Dr. med. Andreas Holstein, Klinik für Gastroenterologie, Klinikum LippeDetmold, Andreas.Holstein@klinikum-lippe.de

Dr. med. Ulf Titze, Institut für Pathologie, Klinikum Lippe-Detmold

Dr. med. Katja Maschuw, Klinik für Abdominalchirurgie, Klinikum Lippe-Detmold

Conflict of interest statement: The authors declare that no conflict of interest exists.

Translated from the original German by David Roseveare.

Cite this as: Holstein A, Titze U, Maschuw K: Intestinal manifestation of polyangiitis with massive bleeding. Dtsch Arztebl Int 2019; 116: 288. DOI: 10.3238/arztebl.2019.0288
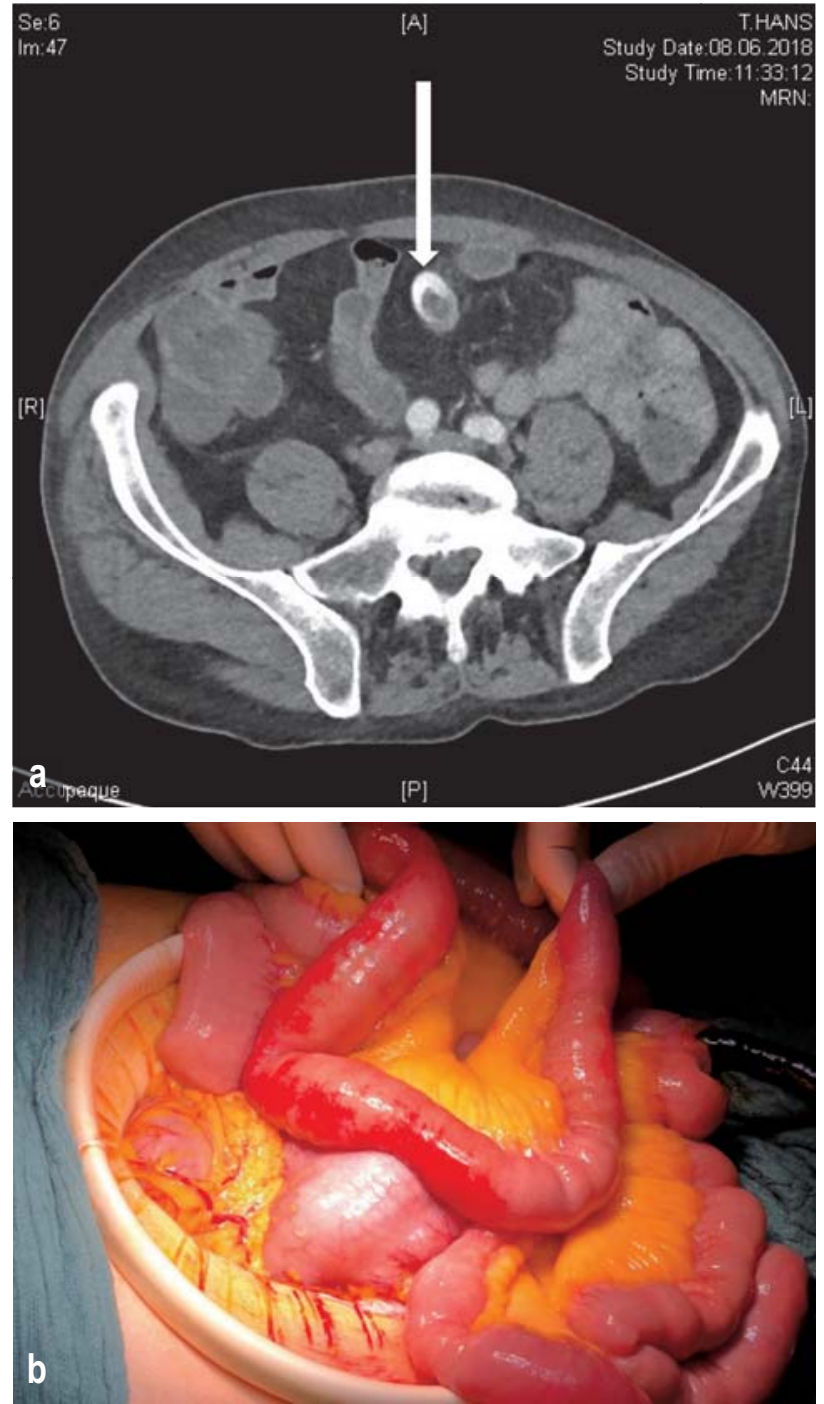

a) Bolus-triggered contrast-enhanced computed tomography of the abdomen (arterial phase, axial plane). Extravasation of the contrast medium in the middle jejunum (arrow)

b) Intraoperative view: segmental inflammation of the ileojejunum with antimesenteric fresh blood covering the visceral peritoneum 